\title{
Constitutional Homeopathy of the Five Elements based on Traditional Chinese Medicine
}

\section{Huang Wei Ling*}

Infectious Diseases, General Practice, Nutrition, Acupuncture and Pain Management Specialist, Medical Acupuncture and Pain Management Clinic, Franca, São Paulo, Brazil

*Corresponding Author: Huang Wei Ling, Infectious Diseases, General Practice, Nutrition, Acupuncture and Pain Management Specialist, Medical Acupuncture and Pain Management Clinic, Franca, São Paulo, Brazil.
Received: May 02, 2020

Published: July 01, 2020

(C) All rights are reserved by Huang Wei Ling.

\section{Abstract}

Introduction: Homeopathy is based on the study of the symptoms caused by each substance given to a normal subject, and then applied to each patient who presents similar symptoms (similimum). However, there is still doubt regarding exactly the origin of these symptoms and how the medication act in the energy point of view.

Purpose: To demonstrate that the signs and symptoms presented by the patients could be related to the Five Elements theory (Wood, Fire, Earth, Metal and Water) of traditional Chinese medicine and to expose the development of specific treatment with homeopathy medications for each massive organ of the Five Elements theory, treating the root and not only the symptom.

Methods: Observational studies were conducted from Western medicine, homeopathic medicine, and traditional Chinese medicine. These different types of reasoning were compiled on the metaphor of the tree, a diagram comparing the differences between the three approaches.

Results: The diagram showed the roots as the Five Elements (Wood-Liver-Phosphorus; Fire-Heart-Sulphur; Earth-Spleen-Calcaria carbonica; Metal-Lung-Silicia; Water-Kidney-Natrum muriaticum), the branches representing each specialty in Western medicine, the leaves of each branch representing the signs and symptoms.

Conclusion: Instead of treating the symptoms presented by the patients using homeopathic medications according to Western medicine reasoning (horizontal model), the author proposes the premise of the use of traditional Chinese medicine, in an energybased treatment (vertical model). Focusing on the root of the problem and not only on the symptoms.

Keywords: Homeopathy; Five Elements Theory; Traditional Chinese Medicine

\section{Introduction}

After 28 years of the graduation of the author (1992) as a medical doctor, presenting six medical specialties, the author perceived the need of studying homeopathy, as she was treating her patients with the use of acupuncture and Chinese herbs and the access to the Chinese herbs medications was very difficult in Brazil. When she started her studies on homeopathy, she already had formation in Western medicine and on traditional Chinese medicine (TCM).

In her studies, she found that homeopathy was a medical specialty in which the literature describes the signs and symptoms that the medication could treat, according to the similarity with the signs and symptoms presented by the patient (similimum).

Citation: Huang Wei Ling. "Constitutional Homeopathy of the Five Elements based on Traditional Chinese Medicine". Acta Scientific Medical Sciences 4.7 (2020): 57-69. 
The author found difficulty in applying the ideas she was studying, because there was no clinical reasoning, but a list of medications to be memorized. The process of diagnosing the patient was very similar to the one done in Western medicine, and Western medicine focuses mainly on the symptoms. The homeopathy treatment would treat only the symptoms as well.

In this few years of study as the author is also specialized in acupuncture, she found the theory of Constitutional Acupuncture of the Five Elements developed by J. R. Worsley, an Englishman. His research was developed between the sixties and the seventies, in which the scholar described the personality characteristics of each element in the Five Elements theory, to be used in acupuncture treatment [1].

The idea of relating the theory presented by J.R. Worsley and homeopathy started during a homeopathy course in Brazil. When reading Constitutional Acupuncture Book of Five Elements, a possibility appeared. The possibility of connecting the Acupuncture of the Five Elements theory with the homeopathy theory [1].

In the J. R. Worsley theory, the emotional features of each constitutional element are described. The reasoning used by J.R. Worsley was very complex and hard to be used on the clinical practice, so, the author developed a model for homeopathy used focused on the replenishment of the energy of the Five Elements, with the main goal of toning the five massive organs and to treat all signs, symptoms, and pathologies presented by the patient in their deepest level, at the root of the problem, not only treating the symptom [1].

\section{Purpose of the Study}

The purpose of this study is to bring a new way of thinking when treating patients using homeopathic medicine. For this, the author unites the knowledge of Western medicine and those of traditional Chinese medicine, in addition to the existing knowledge in homeopathy today.

\section{Methods}

An observational study was carried out bringing together theories of homeopathy, traditional Chinese medicine and Western medicine, to illustrate, a case report was also used, relating the diagnosis and treatment of a patient who was treated according to the theory proposed in the study, and presented significant and stable improvement.

\section{Case Report}

A patient named B.F.S, 36-year-old female.

The patient searched for treatment with ancient medical tools and traditional Chinese medicine due to symptoms of insomnia, anxiety, pain on the knees, constant inflammations and infections on the urinary tract, mainly on the kidneys, memory loss and weight gain.

The background of the patient showed that she had a drop in her life quality after having her second daughter. The first symptoms were problems to sleep. Previously to her second daughter's birth, the patient said she would sleep well and have a very repairing sleep. After, however, she reported to have light sleep and would feel tired all day long. She also reported feeling very anxious, in a constant alert state. The lack of restoring sleep would lead to stress and affect other areas.

She gained weight, as she started to eat more due to the stress. She reported feeling constantly irritated and tired. She had dark circles around her eyes as well. She would eat badly and drink almost nothing of water.

Due to the poor water consumption, the patient started to present problems in her kidneys. Mainly mild infections (cystitis and urinary infections, as well as kidney stones). The standard treatments performed with Western medicine would work for a while, but she would relapse as soon as the medications were withdrawn.

Mentally, the patient also had symptoms of memory loss, guilty of not being able to interact with her daughters as well as she wanted, due to the physical and mental tiredness. She also had strong pain on the knees. She searched for orthopedic treatment and nothing was found.

The patient was first diagnosed according to traditional Chinese Medicine, her diagnosis was Blood and Kidney-Yang deficiency.

Treatment was started with Chinese dietary counseling, which consisted of avoiding dairy products, cold drinks, raw food, sweets, coffee, soda and matte tea. Besides it, it was recommended to avoid frying, chocolate, eggs, honey, coconut, alcoholic beverages and melted cheese. During the night, it was recommended for the patient to eat earlier (around 17:00 or 18:00), eating only foods who grow below the earth (potatoes, cassava, carrots, onions, beet, 
parsnip, etc). The foods, who grow above the earth, should only be eaten at breakfast or lunch.

Auricular acupuncture associated with apex ear bloodletting was also used.

The patient also received chakras measurement, which showed that the entire patient's chakras' energy was depleted. From level 1 of 8,1 being the minimum and 8 being normal, all patient's chakras were rated in level 1.

A treatment to replenish the energy of the chakras of the patient was also started, with the use of homeopathy (according to the theory described in this study) and crystal-based medications.

The homeopathies prescribed were Sulphur 30CHXX-20 (single dose), Calcarea carbonica 30CHXX-20 (single dose), Silicea 30CHXX-20 (single dose), Natrum muriaticum 30CHXX-20 (single dose), Phosphorus 30CHXX-20. The homeopathies were prescribed to be taken in a single dose with a hiatus of 3 days between the medications, necessarily on the sequence described. Two months later, a new sequence of treatment was started, with the same medications taken on the same order, but now with 200CHXX-20 instead of 30 CHXX-20. Two months later, a new sequence of treatment was started, as the others, with the same medications taken on the same order, now with 1000CHXX-20 instead of 200CHXX-20. Two months later, a new sequence of treatment was started, as the others, with the same medications taken on the same order, now with 10000CHXX-20 instead of 1000CHXX-20. Two months later, a new sequence of treatment was started, as the others, with the same medications taken on the same order, now with 50000CHXX-20 instead of 10000CHXX.

\section{Results}

After these changes, there was a rapid response, which first appeared for the patient as improvement in her sleep. The patient started to be able to sleep better and earlier, and had improvement of the knee pain, did not have any new infections or kidney problems. Her mind suffered improvement as well, feeling less anxious and with better memory.

\section{Discussion}

As stated by several studies of the author [2-7], the concept of wellness and health of the Western medical schools and culture is focused on the symptoms, and in each organ affected by the symptoms felt. According to traditional Chinese medicine studies, and other ancient medical traditions, the concepts of wellness and health are based in a major state of equilibrium considering the environment in which the individual is inserted, the patient's emotions and the diet. In traditional Chinese medicine, all the organs are in a dynamic balance, depending on each other for the body work well as a system, differently from what is seen nowadays in Western medicine [8].

This equilibrium is found in the balance of all the energies present in the body. The concept of vital energy is not discussed in the medical schools, and their ways of diagnosis and treatment, as well as reasoning, are centered in small-localized spots. However, as the author was able to notice in her daily practice treating patients with the use of traditional Chinese medicine, the logic used, as well as the diets and other tools of treatment proposed, can demonstrate significant efficacy in the treatment of the most varied pathologies [2-7].

Involved in this base of studies, the author started her researches in the homeopathy field, and there, a gap was found. The homeopathy treatment, even effective, was considered not predictable for several scholars, having different effects in different patients [9]. The law of the similar, used as a cornerstone for homeopathy nowadays, does not address or explain the energy mechanisms in which homeopathy acts. The procedure is done memorizing or reading the simillimum between the drugs and the patient's symptoms. The pathway of the functioning of homeopathy medication itself is not well understood [10].

A proposal then appeared, when using homeopathy allied to traditional Chinese medicine tools and principles, great efficacy could be observed [2-7].

To understand why it will be necessary to state first the main principles of traditional Chinese medicine that can connect with homeopathy mechanisms of action.

The origins of the study: Treating the patient in the root-level

The treatment of the patient in the case report, as well as all other patients of the author, was based on the analysis of one specific case the author had in 2007 . The patient in question presented symptoms of pain in the legs and received treatment with Chinese Dietary counseling, auricular acupuncture and systemic 
acupuncture associated with apex ear bloodletting to treat these symptoms, according to his energy imbalances. In the specific case of this patient, he was diagnosed with Kidney-Yang deficiency, according to TCM [2-7].

The patient presented an improvement of his pain in the legs after 10 acupuncture sessions and returned to the clinic to be evaluated again. On this occasion, he revealed to the author that he also had a major improvement in a symptom the author was not aware he had: he was being treated for glaucoma in the last 40 years, with no significant improvement.

For the first time, his intraocular pressure diminished from 40 $\mathrm{mmHg}$ to $17 \mathrm{mmHg}$. The treatment for Kidney-Yang deficiency not only improved his symptoms of pain in the legs but also improved his intraocular pressure [2-7].

This was part of a study presented in 2015, at an acupuncture research conference at the Faculty of Medicine of Harvard University in Boston, entitled Acupuncture viewed holistically can treat all the patient's diseases simultaneously - A case study. The summary of this study states that if we treat the patients' energy imbalances (Figure 1), we will treat all the patient's symptoms at the same time; even if the doctor does not know the patient has such a symptom. With this type of reasoning, we will be able to treat all dis-

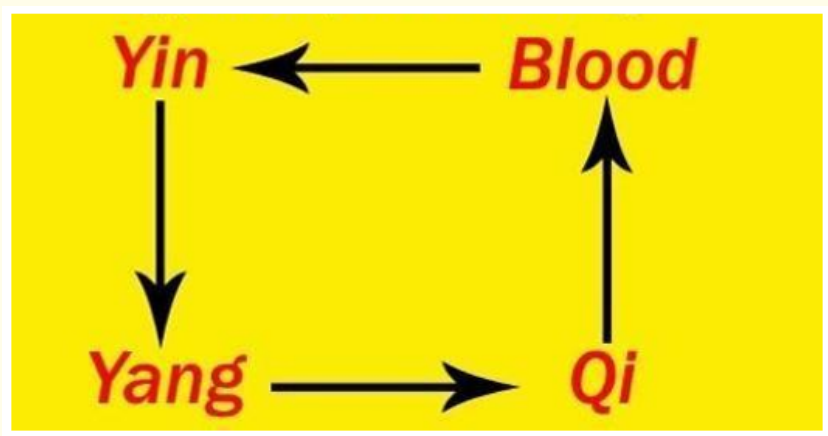

Figure 1: Yin, Yang, Qi and Blood.

eases of all specialties at the same time, as we treat in this case, the root of the problems and not only the symptoms. This idea is what the author has been trying to bring for homeopathy as well [2-7].

In other studies of the author, the metaphor of the tree was placed to explain better the relation between Western and traditional Chinese medicine, as well as the concepts of leaf-level and root-level developed by the author in several of her studies. These concepts are constantly helpful to comprehend the logic underlying the treatment done in the patient of this case report, and other

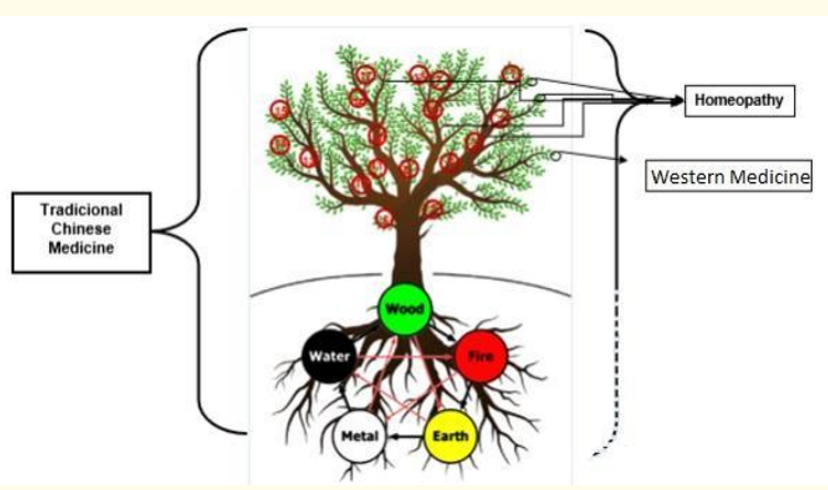

Figure 2: Schematic drawing of the tree as a metaphor between traditional Chinese medicine, homeopathy and Western medicine.

patients previously studied. This metaphor will be placed here for clarifying purposes (Figure 2) [2-7].

This work has the objective to link what has already been described in the homeopathic literature and the teachings of traditional Chinese medicine. The main goal of connecting both theories is to explain the energy flow mechanisms and how can they be applied to homeopathy theories. In this schematic drawing of the tree, it is possible to visualize the root, trunk, several branches and coming out of each of these branches, many leaves (Figure 2) [2-7].

The schematic drawing can be used as a metaphor for the relation between homeopathy, Western and traditional Chinese medicine. In this representation, each medical specialty is represented by a branch, and the leaves of each branch represent the symptoms and diseases related to each specialty. The diagnosis and treatments of Western medicine focus in the leaves level, therefore, treatment is focused on the patient's symptoms [2-7].

Homeopathy, on the other hand, treats many symptoms of a diversity of specialties at the same time, and in many cases, it can treat the root. However, the physician, when using homeopathy, cannot explain the exact mechanism of action and/or the routes of energy flow $[9,10]$, responsible for the patient's improvement. This unfamiliarity is represented in the image by the dotted line under 
the earth, on the right side of Figure 2.

The left line, which represents traditional Chinese medicine perspective is solid because TCM can explain how energy flows in the body [8]. In traditional Chinese medicine, various symptoms of different specialties can be treated at the same time [2-7], as it considers the root of the problem. The root of the problem is represented by the Five Elements Theory and Yin and Yang theory.

Everything on the universe is formed by energy, some materialized and some are not. The materialized part is on the leaf-level and the one that cannot be seen is on the root-level. There is an influence on the environment on the whole tree, and there is a communication among the root of the tree to the branches and leaves, through the energy meridians, in a dynamic process. When there is an energy imbalance (a disturbance on the root), this flow

\begin{tabular}{|c|c|c|c|c|}
\hline \multicolumn{5}{|c|}{ Progression of Health to Disease } \\
\hline & Organ & Exams & $\begin{array}{c}\text { Energy } \\
\text { Reserve }\end{array}$ & Symptom \\
\hline Phase 1 & $\begin{array}{c}\text { Slowing of } \\
\text { the organ } \\
\text { functions }\end{array}$ & Normal & $\begin{array}{c}\text { Energy } \\
\text { reserves } \\
\text { - normal }\end{array}$ & $\begin{array}{c}\text { Without } \\
\text { clinical }\end{array}$ \\
\cline { 4 - 5 } Phase 2 & $\begin{array}{c}\text { Slowing of } \\
\text { the organ } \\
\text { functions }\end{array}$ & Normal & $\begin{array}{c}\text { Consumption of } \\
\text { internal energy } \\
\text { reserves }\end{array}$ & $\begin{array}{c}\text { With } \\
\text { symptoms in } \\
\text { other organs }\end{array}$ \\
\hline Phase 3 & $\begin{array}{c}\text { Slowing of } \\
\text { the organ } \\
\text { functions }\end{array}$ & Normal & $\begin{array}{c}\text { Consumption of } \\
\text { internal energy } \\
\text { reserves }\end{array}$ & $\begin{array}{c}\text { Wympth } \\
\text { symp in } \\
\text { same organ }\end{array}$ \\
\hline Phase 4 & $\begin{array}{c}\text { Reversible } \\
\text { Cellular } \\
\text { Lesion }\end{array}$ & $\begin{array}{c}\text { Little al- } \\
\text { teration }\end{array}$ & $\begin{array}{c}\text { Consumption of } \\
\text { blood reserves }\end{array}$ & $\begin{array}{c}\text { Curable } \\
\text { disease }\end{array}$ \\
\hline Phase 5 & $\begin{array}{c}\text { Irreversible } \\
\text { Cellular } \\
\text { Lesion }\end{array}$ & $\begin{array}{c}\text { Excessi- } \\
\text { ve alte- } \\
\text { ration }\end{array}$ & $\begin{array}{c}\text { Metabolic } \\
\text { Exhaustion }\end{array}$ & $\begin{array}{c}\text { Incurable } \\
\text { disease }\end{array}$ \\
\hline
\end{tabular}

Table 1: Progression of health to disease.

is disrupted, and the energy does not achieve the higher levels (branches and leaves) leading to the formation of symptoms and diseases. This idea represents why there are levels of progression from health to disease, as showed in table 1.

Still based on the energy concept, a scholar divided the phases of the disease into a scheme considering the energy level. Before a disease is diagnosed at the laboratory or by complementary tests, there has already been an alteration in the energy level, where the patients have symptoms but the laboratory tests are still normal
[2-7].

Western medicine performs the diagnosis in phases 4 and 5 when there is laboratory alteration. The phases 1 to 3 are energy alterations, which are not shown in the exams, but the patient already complains of symptoms. The diagnosis in Western medicine is delayed because it may take more than 5 years for the energy imbalances to reflect themselves as alterations in the laboratory exams [2-7].

At phase 4 the laboratory exams show some alterations, and the disease is still curable, and at phase 5 , the exams are very altered, and the cellular damage is irreversible and the disease incurable [2-7].

Five elements and Yin and Yang theory

The Five Elements theory is a scheme that many traditional Chinese fields use to explain a wide array of phenomena, from cosmic cycles to the interaction between internal organs. It is part of the cornerstones of traditional Chinese medicine philosophy and is deeply linked to Yin and Yang theory $[8,11]$.

Chinese wise men from that time believed everything in the universe was formed by energy, including the human body. Observing nature, they were able to realize how the universe constantly works in pairs: days and nights, female and male, the seasons. They comprehended these processes as cycles of two opposite but complementary energies. They named these two energies Yin and Yang $[8,11]$.

The Yin and Yang symbol, in Figure 3, is divided into two sides. It is also possible to observe how each side has a spot that belongs to the opposite side. The white side represents Yang's energy, which is

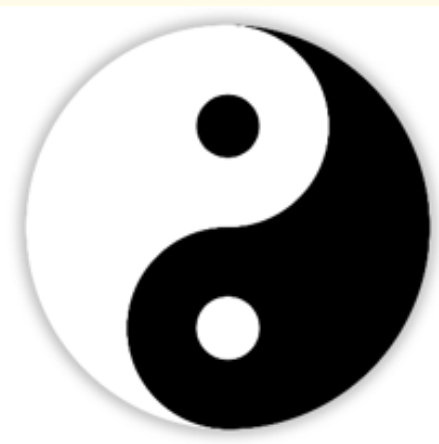

Figure 3: Yin and Yang. 
male, represents light, fire, heat and is the positive side. The black side represents Yin, which is female, and corresponds to the moon, darkness and is the negative side. They are cyclical. When the Yin is in its utmost, the Yang energy will start to grow, and the opposite is true $[8,11]$.

In the graph in figure 4, the different balances and imbalances of Yin and Yang are found. In number 1, the columns representing Yin and Yang are at the same height, which shows balance. This

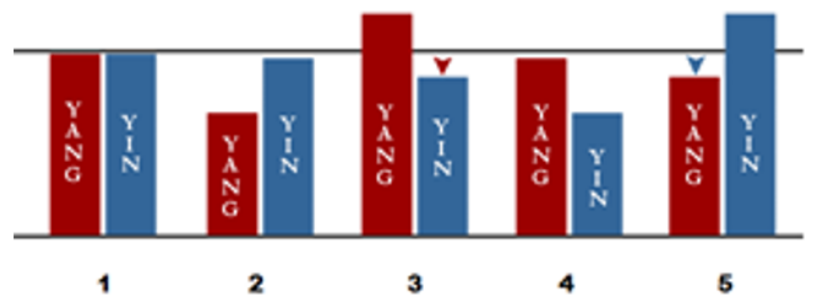

Figure 4: Yin depletion - Yang excess/ Yang depletion - Yin excess.

balance is the objective of the majority of the treatments to achieve health, according to traditional Chinese medicine. When one is smaller or larger than the other is, there is an imbalance as shown in the graph in figure 4. For example, in number 3, where Yang is larger than Yin, the patient may feel hot flashes. This is a very common problem in women during menopause $[8,11]$.

In number 5, where Yang is smaller than Yin, the patient may feel coldness, mainly in the extremities.

In the Five Elements theory, there are four main cycles, or ways of interaction between the elements. The first is the Generation cy-

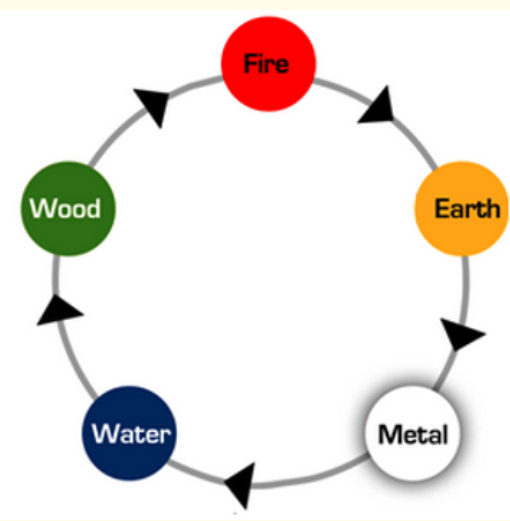

Figure 5: Cycles of generation-five elements theory. cle shown in Figure 5. In this cycle, each element serves as a "mother," which promotes the growth and development of the "child," element. Each element provides a generating force for the element that follows it. Metal generates Water; Water nourishes Wood; Wood feeds Fire; Fire creates Earth/ash; Earth bears Metal $[8,11]$.

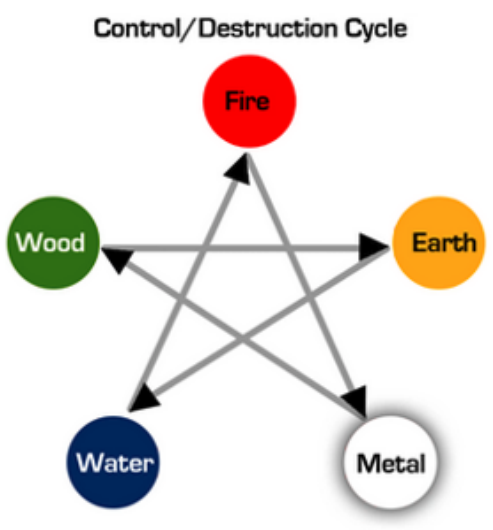

Figure 6: Cycle of control-five elements theory.

The second main cycle is Control cycle. According to the Control cycle theory, in order to keep balance, each element is involved in a checks-and-balances relationship with the following element. Each element controls and is controlled by another element, as showed in figure 6. For example, Fire melts Metal; Metal chops Wood; Wood breaks up Earth; Earth absorbs Water; Water quenches Fire $[8,11]$.

\begin{tabular}{|l|c|c|c|c|c|}
\hline Season & Wood & Fire & Earth & Metal & Water \\
\hline $\begin{array}{l}\text { Develop- } \\
\text { ment stage } \\
\text { or Power }\end{array}$ & Birth & Growth & $\begin{array}{c}\text { Summer's } \\
\text { End }\end{array}$ & Autumn & Winter \\
\hline Climate & Wind & Heat & Humidity & Dryness & Cold \\
\hline Senses & $\begin{array}{c}\text { Eyes, } \\
\text { vision and } \\
\text { tears }\end{array}$ & $\begin{array}{c}\text { Language } \\
\text { tongue }\end{array}$ & $\begin{array}{c}\text { Mouth } \\
\text { and taste }\end{array}$ & $\begin{array}{c}\text { Nose and } \\
\text { smell }\end{array}$ & $\begin{array}{c}\text { Ears and } \\
\text { hearing }\end{array}$ \\
\hline $\begin{array}{l}\text { Tissues and } \\
\text { parts of the } \\
\text { body }\end{array}$ & $\begin{array}{c}\text { Ligaments } \\
\text { tend } \\
\text { tendons }\end{array}$ & $\begin{array}{c}\text { Blood and } \\
\text { vessels }\end{array}$ & Muscles \\
and flesh & $\begin{array}{c}\text { Skin and } \\
\text { nose }\end{array}$ & $\begin{array}{c}\text { Bones, } \\
\text { bone } \\
\text { marrow } \\
\text { and hair }\end{array}$ \\
\hline Residuals & $\begin{array}{c}\text { Nails, } \\
\text { ligament } \\
\text { residuals }\end{array}$ & $\begin{array}{c}\text { Hair, blood } \\
\text { residual }\end{array}$ & $\begin{array}{l}\text { Fat, flash } \\
\text { residual }\end{array}$ & $\begin{array}{c}\text { Body } \\
\text { hair, skin } \\
\text { residual }\end{array}$ & $\begin{array}{c}\text { Teeth, } \\
\text { bone } \\
\text { residual }\end{array}$ \\
\hline Taste & Sour & Bitter & Sweet & Peppery & Salty \\
\hline
\end{tabular}

Table 2: Secondary resonance of the five elements. 
In Table 2, it is possible to see the secondary characteristics of each element, in the Five Elements theory. Each element has a relationship with one of the four seasons, a major importance in the development stages, and suffers influence by a specific external pathogenic factor. Each element is responsible for a sensorial external organ, tissues, parts of the body, and residuals. Each element also suffers influence from different tastes $[8,11]$.

Wood taste is sour, Fire taste is bitter, Earth taste is sweet, the Metal taste is peppery and Water taste is salty. For achieving balance between these elements, an individual should eat all this flavors during the period of one day, without craving or withdrawing any of the tastes. The sweet taste is related to the subtle sweetness of beet or corn, not being associated with actual sugar, which, when consumed excessively will imbalance the Earth meridian instead of nourishing it. When the individual craves more for one specific flavor, this might mean that the meridian associated with the taste may be imbalanced.

Everything in the world, in our universe, can be understood in light of the Theories of Yin and Yang and the Five Elements. Homeopathy could also be explained in light of these principles. These theories could lead us to a deeper vision in the functioning of the flow of energy, which could be what is referred to in homeopathy as the vital force or $Q i$ in traditional Chinese medicine. This vision may be a very useful complement to the methodology used in homeopathic diagnosis nowadays $[8,11]$.

For each solid organ in our body, there is an external sensorial organ, which is commanded by it. For example, Wood represents the Liver and the external sensorial organ it commands is the eye, whose function is vision. Other function of the Liver meridian on the energy point of view is to harmonizes the $Q i$ flow throughout the body $[8,11]$.

Fire represents the Heart and the external sensorial organ, in this case, is the tongue, whose function is language. The Heart meridian is responsible for communication and sleep and vitalizing the structures of the body $[8,11]$.

Earth is the Spleen, which commands the mouth, whose function is taste. Other function of the Spleen is to absorb the nutrients and maintain the blood inside the blood vessels. Metal is the Lung commanding the nose, whose function is the smell. Other function of the Lung meridian is to receive and absorb Qi as well as distribute $Q i$ on the body. Water is the Kidney and it commands the ears, whose function is hearing. The Kidney meridian also commands the bones, teeth, reproduction and sexuality $[8,11]$.

This information is important for the homeopathic professional because the visible symptoms of external sensorial organs are just the tip of the iceberg. The cause, which is in the root, may be found through this relation. For example, when the patient has an eye problem, the physician may have good results treating the Liver meridian, as showed table $2[8,11]$.

Constitutional homeopathy of the five elements and their emotional characteristics

According to the book Constitutional Acupuncture of the Five Elements, there are the following emotional characteristics, described in table 3. The main idea of this theory is to identify the most significant and constitutional element in each patient throughout emotional characteristics [1].

These descriptions are extensive and complex. The Wood Constitutional Factor, when balanced, is able to observe the best moment to develop and grow and knows how to wait. It has a strong sense of justice and is deeply attached to the concepts of right and wrong. The Fire Constitutional Factor, when balanced, is able to give and receive love, knowing the degrees of intimacy and emotion. It is responsible for happiness and joy, and it is a warm presence. The Earth Constitutional Factor is maternal. When balanced, it can give support and emotional balance to others and to themselves. The Metal Constitutional Factor can capture the richness of life and be able to move on, after sad situations or grief, helping others to do so. The Water Constitutional Factor is cautious. When balanced, it is able to recognize the danger and protect the others and themselves from risks [1]. In the used example, the Constitutional factor of the patient described in the case report, was not used to classify each element she belongs to. This patient was treated without these emotional features and the method used will be further explained.

\section{Homeopathy medications in the Five Elements theory}

On the daily practice of the author, it was possible to notice that the symptoms presented by the patient were linked with lack of energy of the five internal organs (Liver, Heart, Spleen-pancreas, Lungs, and Kidneys), correspondent to the five elements (Wood, Fire, Earth, Metal e Water) in the Five Elements theory on traditional Chinese medicine. 


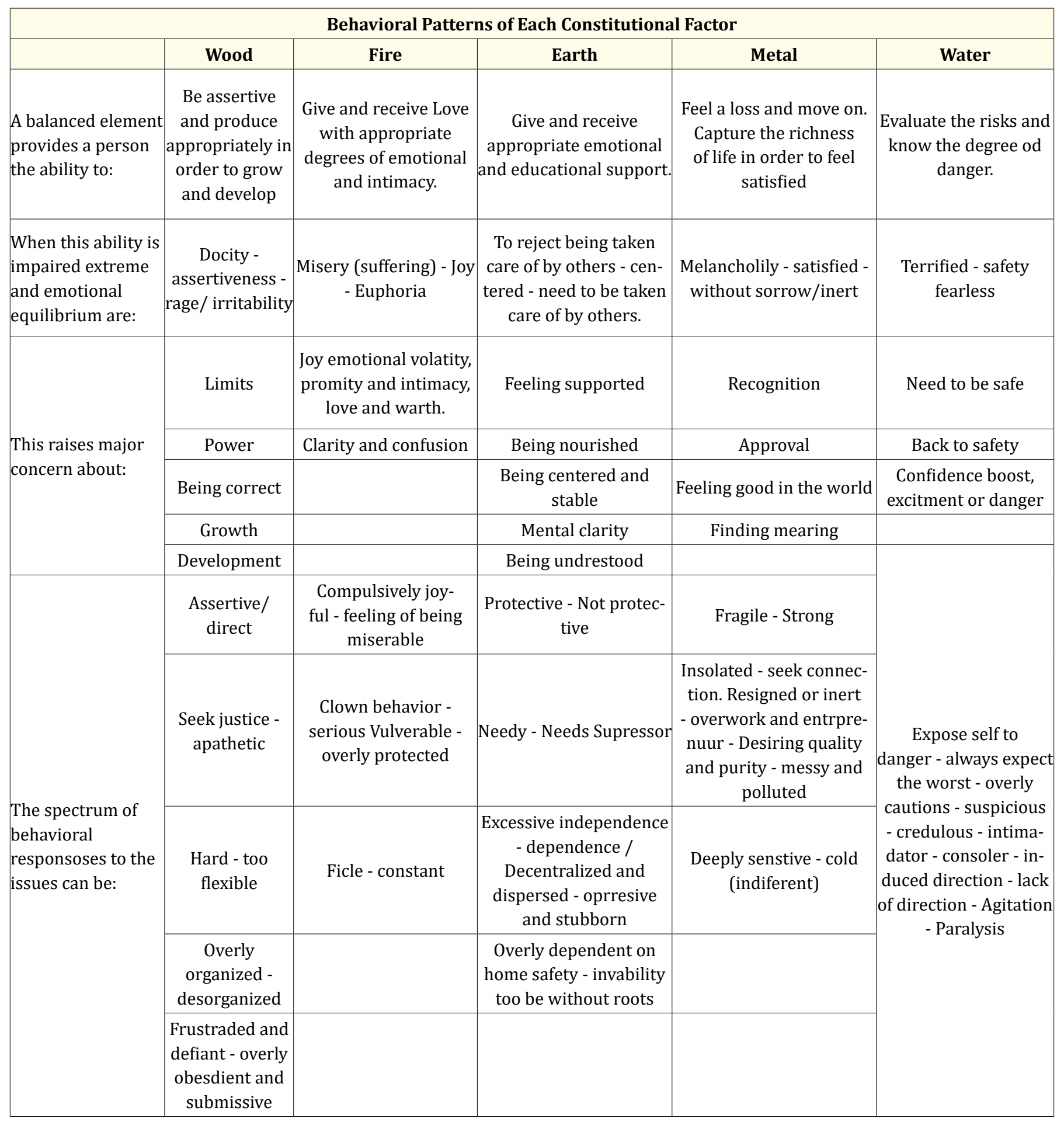

Table 3: Behavioral patterns of each constitutional factor. 
Five medications were chosen to represent each element in the Five Elements theory. The homeopathy medications chosen are

\begin{tabular}{|l|c|}
\hline \multicolumn{1}{|c|}{ Five Elements } & Homeopathy Medications \\
\hline Wood/Liver & Phosphorus \\
\hline Water/Kidney & Natrum muriaticum \\
\hline Fire/ Heart & Sulphur \\
\hline Metal/Lung & Silicea \\
\hline Earth/Spleen & Calcarea carbonica \\
\hline
\end{tabular}

Table 4: Homeopathy medication chosen in the treatment according to the correspondence to the Five Elements theory.

Phosphorus (Wood), Sulphur (Fire), Calcarea carbonica (Earth), Silicea (Metal) and Natrum muriaticum (Water).

These five homeopathy medications were chosen according to the tropism with each massive organs or elements of Five Elements Theory, to replenish the energy of these organs. They are shown in Table 4.

The tropism between the medications chosen and the massive organs can be found in literature. For example, on the Complete Book of Homeopathy, written by Michael Weiner and Kathleen Goss, it is stated that Phosphorus is a very useful Liver remedy [12].

Regarding Sulphur, on the Matéria Médica Homeopática Interpretada book, written by Carlos Brunini and Mário Sérgio Giorgi, it is stated that Sulphur is related with the Fire element because the origin of Sulphur is connected with volcanos and eruptions [13].

Regarding Calcarea carbonica, the book entitled Tratado de Matéria Médica Homeopática, written by Léon Vannier and Jean Poirier, states that Calcarea carbonica is related to the Earth element [14].

Silicea, according to the book Doenças Crônicas from Samuel Hannheman, is associated with the respiratory system [15].

Also, on the Complete Book of Homeopathy, written by Michael Weiner and Kathleen Goss, Natrum muriaticum is associated with the Water element [12].

The chosen scheme of the homeopathies and the Five Elements theory is described in figure 7.

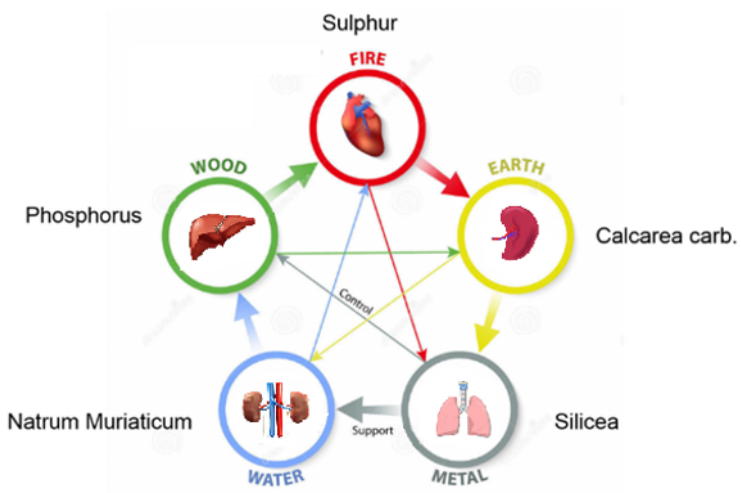

Figure 7: Homeopathy and Five Elements theory.

For example, in the study of the author entitled The Treatment of Asthma Based on Traditional Chinese Medicine and Homeopathy, it is proposed the treatment of asthma symptoms using Natrum muriaticum to treat the Water Element (Kidney), because the patient complained of feeling very cold, demonstrating a Kidney-Yang deficiency. In traditional Chinese medicine, the Kidney is responsible for the production of Yin and Yang in the body. This is why, according to this theory, the patient received Natrum muriaticum to tone the energy of the Kidney, causing an improvement in the asthma symptoms.

If the remedy is well-chosen, why some patients do not improve completely?

There are situations in homeopathy treatment when the medicine is well chosen but the patient still does not improve. Even Hahnemann who knew how to choose the medicine well, spoke of miasma, "Even the best-chosen remedy fails to act" [16].

One of the goals of this theory is to establish why the best-chosen remedy fails to act. The homeopathy physicians do not comprehend the mechanism promoting homeopathy success yet: the energy level [2-7].

The reasoning of current homeopathy nowadays is done in a way where the information collected is translated into a Western medicine diagnosis, where the process is viewed in a horizontal way as it goes from symptom to symptom (Figure 8) [17-20]. 


\section{HOMEOPATHY}

\section{WESTERN MEDICINE DIAGNOSIS}

The reasoning used is based on the knowledge and diagnosis conducted in Western Medicine. In this perspective of treatment, diseases are treated observing symptoms, not addressing to the root-level of the tree metaphor. The view of this model is horizontal and goes from symptom to symptom.

Figure 8: Reasoning of current homeopathy.

According to the studies of traditional Chinese medicine, homeopathy would not be treating symptoms, but dealing with the patient's energy at the root-level and Western medicine does not deal with energy but with the disease already installed in the body, in phase 4 or 5 of table 1 . According to the metaphor of the tree (Figure 2), Western medicine is not reaching the root of the problem. Therefore, giving a Western medicine diagnosis for a homeopathic treatment is not the best reasoning, once there may be several energy imbalances of several different pathways leading to the same symptom, according to TCM reasoning [2-7].

The horizontal arrow between the word's "homeopathy" and "Western medicine diagnosis" represent that the diagnosis in homeopathy is done according to the diagnosis on Western Medicine, from leaf-to-leaf on the tree metaphor, not involving the root of the problem, on the energy level.

In the process proposed, the reasoning performed by the doctor would be done in a vertical mode, through the signs and symptoms presented by the patient. The physician will observe the tree metaphor and try to diagnose the root of the problem, through the theory of the Five Elements and theory of Yin and Yang [2-7].

The meaning of the vertical arrow between the words' "homeopathy" and "TCM" represents the idea that the diagnosis would be done focused on the energy imbalances, considering the symptom on the leaf-level to perform a diagnosis on the root-level.

\section{Chakras energy meridians and Five Elements theory}

In this study and on other treatments proposed by the author, the theory of the chakras, from Ayurvedic medicine was also used.

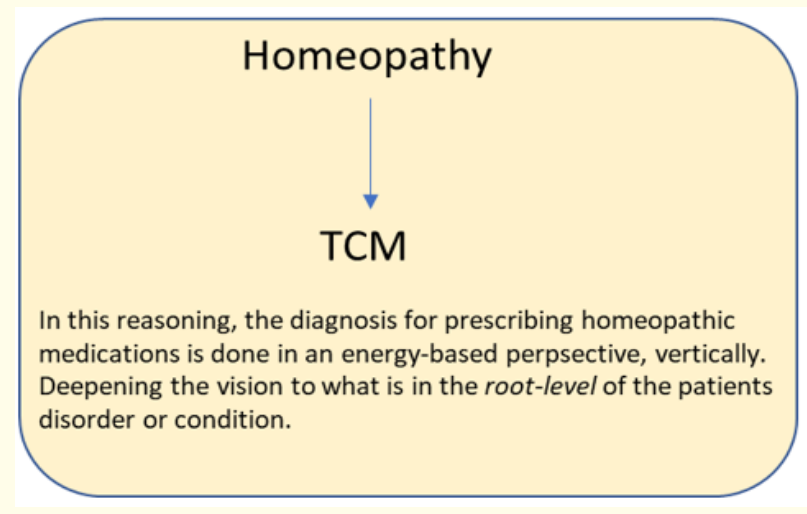

Figure 9: Proposal for a future reasoning of homeopathy.

The reason for their use regards two points. First, the chakras correspond to the Five Elements within the Five Elements theory, as exposed in limited trials in literature. Second, the procedure done in Ayurvedic medicine to measure the chakras is a very simple procedure, called radiesthesia.

Many ancient medical scholars believe the Five Elements theory and the chakras' theory can connect. One example is entitled The Geometry of Emotions: Using Chakra Acupuncture and 5-Phase Theory to Describe Personality Archetypes for Clinical Use. In this study, Chase CR links using chakras measurement with the principles of traditional Chinese medicine, to comprehend the influence of a weakened result in the chakras measurement into the other systems of the body. Although this article is focused in personality archetypes linked to the chakras, it establishes a relationship be- 
tween the Five Elements theory and the seven chakras, in the same way as proposed by the author of this study in previous articles of her [20].

The system the author used for treating the Five Elements was based on this correspondence of the chakras to study the energy level of the five massive organs of the Five Elements theory, instead of using the descriptions of the constitutional factors described on Constitutional Acupuncture of the Five Elements book. As there are

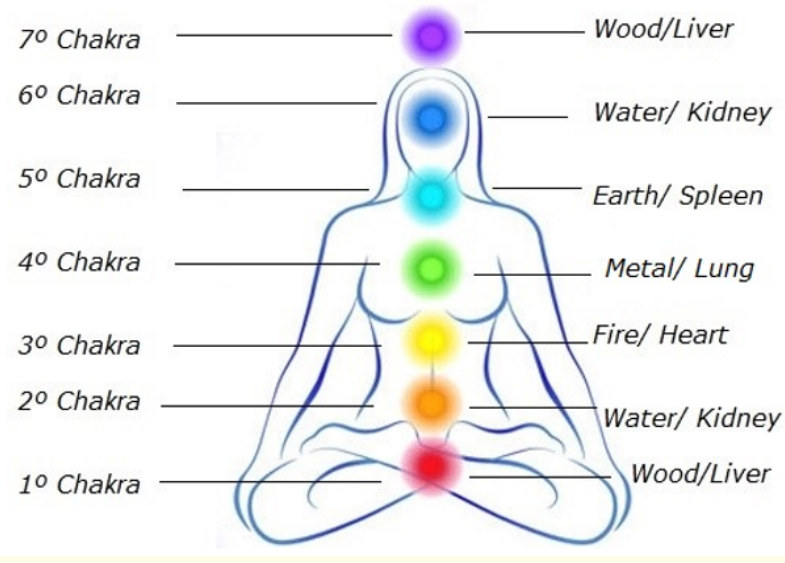

Figure 10: Chakras energy correspondence.

seven chakras and five elements, the seventh chakra is ruled by the first (Wood or Liver), and the sixth chakra is ruled by the second (Water or Kidney). The fifth chakra is ruled by Earth (SpleenPancreas), the fourth is ruled by Metal or Lung, the third is ruled by Fire or Heart. The second is ruled by Water or Kidney and the first chakra is ruled by Wood or Liver, as shown in Figure 10.

The procedure of radiesthesia is done using a crystal pendulum. This pendulum is placed in front of each person chakra (placed as in figure 10). The pendulum may stay still or move clockwise or counterclockwise. These movements are classified in a scale of 1 to 8,1 being the minimum level of energy and 8 the normal level. If the pendulum does not move, the patient has no energy on the evaluated chakra. If it moves clockwise, it will be classified from 1 to 8 according to the intensity of the movement. When the movement is counterclockwise may be external interference, and it has to be studied individually.
Using the chakra centers measurement of the patient on the case report and considering her symptoms, it was possible to use the correspondence of the chakras with the five massive organs and five elements of the Five Elements theory because each chakra is responsible for several body activities. Each massive organ is related to an external sensorial organ, as presented on Table 2.

The main symptoms of the patient were used as a demonstration to show what the symptoms mean on traditional Chinese medicine, being described by the correspondent massive organ and the related chakra. The symptom of insomnia is related to a deficiency of the third chakra, or the Heart in the Five Elements Theory. The symptom of anxiety is a reflex of a deficiency on all the chakras, and according to literature is a deficiency mainly on the second chakra, or the Kidney meridian.

The symptom of pain on the knees is a deficiency of the Kidney meridian and or Liver meridian (second and first chakra, respectively). Infections on the urinary tract are deficiency of Blood and Heat retention (fifth chakra). The symptom of memory loss is related to the Kidney meridian (second chakra). The symptom of weight gain is related to the deficiency in all the chakras, especially on the Kidney meridian (second chakra) or Spleen-pancreas meridian (fifth chakra). The symptom of tiredness is related to deficiency of all the chakras or all massive organs, the irritation is related to Heat retention due to energy deficiency on the chakras, the dark circles around the eyes are a symptom of Kidney deficiency (second chakra), and the lack of willing in drinking water is linked to a deficiency of the Spleen-pancreas, or fifth chakra.

The author has a great knowledge of traditional Chinese medicine, but is not necessary to know exactly the relation between the symptoms and the specific massive organs to use this procedure. Only measuring the chakras of the patient and, according to the results, perform treatment with homeopathy according to Table 4 and Figure 7.

\section{Arndt-schultz law}

The law of Arndt-Schultz was formulated in 1888. It states the effects of different drug concentrations on an individual basis, as demonstrated on Figure 11. The law states "for all substances, small doses stimulate, moderate doses inhibit and overdoses kill" [10-16]. 


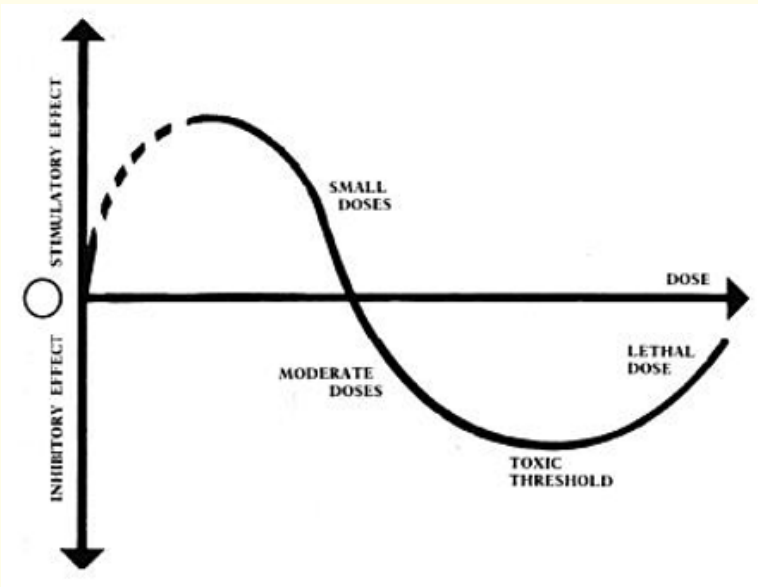

Figure 11: Arndt-schultz law.

According to this law, highly diluted drugs improve organic processes, while high concentrations harm health. When prescribing drugs with high concentrations, according to this law, they would be reducing vital energy. On the specific case of the patient described on the case report, due to the condition of significant deficiency in all the seven chakras, the use of high-diluted medication was preferred instead of the prescription of high-concentrated medications, because they would harm the patients' energy even further [10-16].

Yin and Yang metaphor of traditional Chinese medicine and homeopathy

The body, and therefore, the possible treatments, is not only physical and constituted by organs and tissues. It is formed by

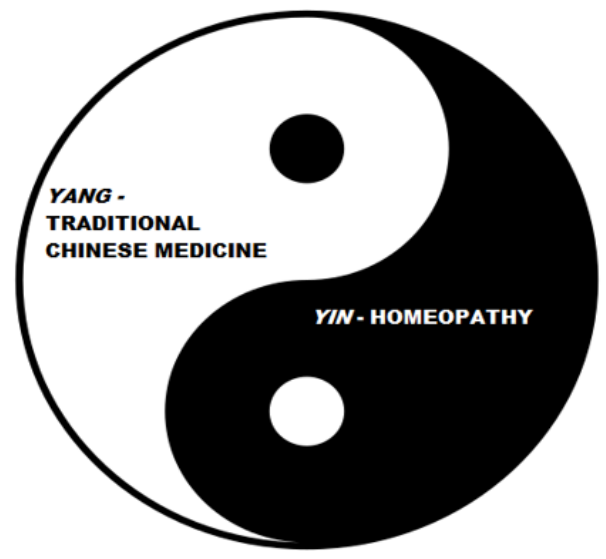

Figure 12: Traditional Chinese medicine and homeopathy - Yin and Yang metaphor. energy. On the reasoning done nowadays, homeopathy is based on what is visible, on Western medicine, treating the symptoms of the diseases and pathologies. However, the diseases and pathologies have an energy background, as the root of the problem. In Figure 12 , the metaphor aims to show the importance of treating the patient based on the energy imbalances and not only the symptoms [2-7].

The study of traditional Chinese medicine is very important for the better comprehension of what is happening inside the body on the energy level, for the homeopathic physician. The metaphor aims to propose an integration of both reasonings for a deeper pathway of treatment [2-7].

\section{Conclusion}

Everything in the world, in our universe, can be understood in light of the Yin and Yang and the Five Elements theories. Homeopathy could also be explained in light of these principles. These theories could lead us to a deeper vision in the functioning of the flow of energy, which could be what is referred to in homeopathy as the vital force or $Q i$ in traditional Chinese medicine. This vision may be a very useful complement to the methodology used in homeopathic diagnosis nowadays.

The doctor may then be able to work with a more complete and integrated view of the human being and manage to treat from the root of the problem and not just the symptom. This new point of view within homeopathy could make it easier for the professional in this area to treat their patients and obtain a better therapeutic result. Considering the Five Elements theory in the diagnosis and treatment of the patient could lead to a deeper and more effective diagnosis and treatment.

\section{Conflict of Interest}

Author declares there is no conflict of interest.

\section{Funding}

Author declares that this study received no funding.

\section{Bibliography}

1. Hicks Angela., et al. "Acupuntura Constitucional dos Cinco Elementos". Translation by Maria Inês Garbino Rodrigues. São Paulo: Publisher. Roca (2007).

2. Huang Wei Ling. "Why are Diabetic Patients Still Having Hyperglycemia despite Diet Regulation, Antiglycemic Medication and Insulin?" International Journal of Diabetes and Metabolic Disorders ISSN 2475-5451. 
3. Huang Wei Ling. "Can Recurrent Furunculosis be Treated without the Use of Antibiotics?" Acta Scientific Microbiology 1.9 (2018): 04-12.

4. Huang Wei Ling. "Could Postsurgical Nosocomial Cellulitis be Treated without the Use of Antibiotics?". Acta Scientific Microbiology 1.9 (2018).

5. Huang WL. "Can Hospital Osteomyelitis Be Treated Without the Use of Antibiotics?" Journal of Microbiology and Infectious Diseases 2.1 (2018): 1-6.

6. Ling HW. "Is it Possible to Treat Community-Acquired and Nosocomial Infections with the Same Method, Without the Use of Antibiotics?" Journal of Applied Microbiological Research 2.2 (2019): 01-13.

7. Huang WL. "Energy Alterations as the Underl Ying Cause of Primary Hypertension". ARC Journal of Nephrology 4.2 (2019): 33-44.

8. Bing Ou Yang and Zhen Gu. "Essentials of Traditional Chinese Medicine". Translated by Lu Yubin. Beijing, China. Edition. Shandong Science and Technology Press (1996).

9. Barollo Célia R. "O que é?... Como é?... E o porquê? da Homeopatia: ciência médica e arte de curar". $3^{\text {rd }}$ Edition. São Paulo: Pharmabooks (2012).

10. Schmidt JM. "Samuel Hahnemann and the principle of similars]". Med Ges Gesch 29 (2010): 151-84.

11. Yin Hui He and Zhang Bai Ne. "Teoria Básica da Medicina Tradicional Chinesa". Editora Atheneu. A causa e o Desenvolvimento das Doenças: 17-49.

12. Michael Weiner and Kathleen Goss. "Complete Book of Homeopathy”. Editor BANTAM BOOKS (1982).

13. Carlos R d Brunnin and Mario Sergio Giorgi. Matéria Médica Homeopática Interpretada". Editora Hipocrática Hahnemanniana (2014).

14. Léon Vannier and Jean Poirer. "Tratado De Matéria Médica Homeopática” (1987).

15. Samuel Hahnemann. "Doenças Crônicas (Matéria Médica)". Editora Homeopática (1998).
16. Hahnemann Samuel. "Exposição da Doutrina Homeopática ou Organon da Arte de Curar". Tradução da $6^{\text {th }}$ edição alemã por David Castro Rezende Filho, Kamil Curi. $5^{\text {th }}$ edição brasileira". São Paulo: Editora Gehsp “Benoit Mure” (2013).

17. Carvalho Marco Antonio P., et al. "Reumatologia Diagnóstico e Tratamento". $4^{\text {th }}$ edição. Rio de Janeiro: Editora Guanabara (2013).

18. Greenberger Norton J. "Current: Diagnóstico and Tratamento Gastroenterologia, Hepatologia and Endoscopia”. $2^{\text {nd }}$ edição. Rio de Janeiro: Editora Dilivros (2013).

19. Veronesi Ricardo and Focaccia Roberto. "Tratado de infectologia". Rio de Janeiro: Editora Atheneu, (1996).

20. Skinner Harry B aand Mcmahon Patrick J. “Current: Diagnóstico e tratamento: Ortopedia". $5^{\text {th }}$ edition. Rio de Janeiro: DiLivros (2013).

21. Perini Mauro. Terapia Dietética Chinesa, Edições Loyola (2002).

22. Guerin Patricia. "Dietoterapia Energética Según los Cinco Elements em La Medicina Tradicional China". Miraguano Ediciones.

23. Huang WL. "Auricular Acupuncture and Chinese Dietary Counselling in the Treatment of Insomnia". Archives of Neurology and Neuro Disorders 3.1 (2020): 01-11.

24. Hippocrates. Aphorism. "Translated by José Dias de Morais". edition. Publisher Martin Claret, São Paulo (2003).

\section{Assets from publication with us}

- Prompt Acknowledgement after receiving the article

- Thorough Double blinded peer review

- Rapid Publication

- Issue of Publication Certificate

- High visibility of your Published work

Website: www.actascientific.com/

Submit Article: www.actascientific.com/submission.php

Email us: editor@actascientific.com

Contact us: +919182824667 